\title{
AOR
}

Selected Papers of \#AolR2020:

The $21^{\text {st }}$ Annual Conference of the

Association of Internet Researchers

Virtual Event / 27-31 October 2020

\section{YOU MADE THIS? I MADE THIS: CULTURES OF (MIS)ATTRIBUTION ON TIKTOK}

\author{
D. Bondy Valdovinos Kaye \\ Queensland University of Technology \\ Aleesha Rodriguez \\ Queensland University of Technology \\ Patrik Wikström \\ Queensland University of Technology
}

\section{Introduction}

In 2019, TikTok captivated international attention as a breakout short-video platform. A key affordance for user-generated content creators on TikTok is how easy the platform makes reproducing popular videos. The video creation interface allows users to make new videos based on the one they were just watching with just one tap. While these features make it fun and easy for users to replicate popular videos, it can also obscure the identity of the creators who created the 'original' content being reused. Furthermore, users can freely reuse popular formats, audio clips, or even licensed music without any connection to the original source with impunity. In this way, TikTok engenders a culture of misattribution. Using a combination of an app walkthrough, a bespoke data scraping tool, content analysis, and a series of qualitative case studies, this study explores the contradictory logic of authorship and how (mis)attribution is shaping cultural production and platform practices on TikTok.

\section{Literature Review}

Legal studies situates creative attribution within broader bodies of work on copyright (Posner, 2007). One's right to be attributed to original works of their creation is protected as a moral right of copyright (Hansmann \& Santelli, 1997). The moral right of attribution becomes more valuable to individuals in non-commercial digital communities who shift fluidly between being users of others' content and authors of their own original

Kaye, D.B.V., Rodriguez, A., \& Wikström, P. (2020, October). You made this? I made this: Cultures of (mis)attribution on TikTok. Paper presented at AolR 2020: The $21^{\text {th }}$ Annual Conference of the Association of Internet Researchers. Virtual Event: AolR. Retrieved from http://spir.aoir.org. 
works (Meese, 2018). Content creation platform affordances (Nagy \& Neff, 2015) have been found to play an important role in mediating norms of authorship, ownership, and attribution in digital content spaces (Meese, 2014). The platform infrastructures, markets, and governance (Nieborg \& Poell, 2018) of TikTok make it a highly 'spreadable' platform (Jenkins et al., 2013). Issues with attribution on spreadable social media platforms has been noted previously among creative communities (Perkel, 2016; Fiesler \& Bruckman, 2014) as well as among everyday 'mundane' platform users (Meese and Hagedorn, 2019). Compared to users in creative communities, mundane users are frequently and incidentally involved in copyright infringement as part of their everyday activity (Tehranian, 2007). Further, certain platform affordances may incidentally facilitate copyright infringement through their everyday use (Tan, 2018).

Drawing from interviews with Reddit, Twitter, and Facebook users, Meese and Hagedorn observed, "in the absence of specific guidance from copyright law or platforms, people are gradually developing practices around content sharing," (p. 8). In addition to specific copyright guidance being largely absent on TikTok, its video creation features amplify and exacerbate attributional issues. TikTok uses an automatic attribution system for audio content, which designates the 'original creator' of audio clips or songs uploaded. Automatic attribution has been found to be inadequate and impersonal in creative communities online that heavily feature the creative reuse of others' works (Monroy-Hernandez et al., 2011). TikTok's automatic attribution system is often responsible for misattribution. In response to these unique circumstances, everyday users of TikTok are developing new practices and cultures, which this study explores using a mixed-methodological approach.

\section{Methodology}

Data for this study were collected from an app walkthrough (Light et al., 2018) and a sample of TikTok videos systematically scraped from TikTok's Web player. Two researchers first conducted an app walkthrough of TikTok in February 2020 to identify the features, everyday uses, and terms of use (ToU) that shape attribution practices on TikTok. We then collected a sample of TikTok $(n=999)$ videos using a bespoke data scraping tool for \#fyp, or 'for you page', TikTok's default content viewing page. The scraping tool, developed in Python, captured audio-visual data (i.e. TikTok videos), their associated metadata (e.g. usernames; hashtags; likes/shares/comments), and data related to audio (i.e. original audio; audio available on TikTok's audio library; audio available on Spotify). After scraping our video sample we developed a codebook based on our research question and initial observations, and then identified a subsample of case study videos for qualitative analysis. Using TikTok's platform features we followed the digital traces of the audio within the case study videos. This entailed navigating multiple platform interfaces, user profiles, and videos which allowed us to intimately observe cultures of (mis)attribution. All data was de-identified for analysis and reporting.

\section{Initial Findings and Progress}

Initial findings indicate several features that obscure proper attribution on TikTok. Descriptive results from our scrape indicate that $67 \%(n=672)$ of our sample $(n=999)$ are 
instances where the automatic attribution system has worked as intended and proper attribution has taken place. Whereas $33 \%(n=327)$ of videos in the sample were found to be misattributed. We identified three distinct practices that illustrate cultures of (mis)attribution on TikTok. The first involves a song in a viral video that is misattributed in TikTok's automatic attribution system, the second involves a creator utilizing the platform features (such as video text and hashtags) to manually give credit to the original author of the audio, and the third involves a creator who uses an original song in a TikTok video that is not available in the TikTok library nor on any other digital music platforms (i.e. Spotify; YouTube; Soundcloud). Currently, we have completed our data collection and analysis, and have drafted a manuscript for publication.

\section{References}

Fiesler, Casey, and Amy Bruckman. 2014. "Remixers' Understandings of Fair Use Online." Proceedings of the ACM Conference on Computer Supported Cooperative Work, CSCW, 1023-32. https://doi.org/10.1145/2531602.2531695.

Hansmann, Henry, and Marina Santilli. 1997. "Authors' and Artists' Moral Rights: A Comparative Legal and Economic Analysis." The Journal of Legal Studies 26, no. 1: 95+. https://doi.org/10.1086/467990.

Jenkins, Henry, Sam Ford, and Joshua Green. 2013. Spreadable Media Culture. New York: New York University Press.

Light, Ben, Jean Burgess, and Stefanie Duguay. 2018. "The Walkthrough Method: An Approach to the Study of Apps." New Media and Society 20, no. 3: 881-900. https://doi.org/10.1177/1461444816675438.

Meese, James. 2014. "It Belongs to the Internet: Animal Images , Attribution Norms and the Politics of Amateur Media Production." M/C Journal 17, no. 2: 1-6.

Meese, James. 2018. Authors, Users and Pirates: Copyright Law and Subjectivity. Cambridge, MA: MIT Press.

Meese, James, and Jennifer Hagedorn. 2019. "Mundane Content on Social Media: Creation, Circulation, and the Copyright Problem." Social Media + Society 5, no. 2: 205630511983919. https://doi.org/10.1177/2056305119839190.

Monroy-Hernandez, Andres, Benjamin Mako Hill, Jazmin Gonzalez-Rivero, and Danah Boyd. 2011. "Computers Can't Give Credit: How Automatic Attribution Falls Short in an Online Remixing Community." Conference on Human Factors in Computing Systems Proceedings, 3421-30. https://doi.org/10.1145/1978942.1979452.

Nagy, Peter, and Gina Neff. 2015. "Imagined Affordance: Reconstructing a Keyword for Communication Theory." Social Media+Society 1, no. 2: 1-9. https://doi.org/doi:10.1177/2056305115603385. 
Nieborg, David B., and Thomas Poell. 2018. "The Platformization of Cultural Production: Theorizing the Contingent Cultural Commodity." New Media and Society 20, no. 11: 4275-92. https://doi.org/10.1177/1461444818769694.

Perkel, Dan. 2016. "Share Wars: Sharing, Theft, and the Everyday Production of Web 2.0 on DeviantArt." First Monday 21, no. 6: 1-24.

Posner, Richard A. 2007. The Little Book of Plagiarism. New York: Pantheon Books.

Tan, Corinne. 2018. Regulating Content on Social Media: Copyright, Terms of Service and Technological Features. London: UCL Press. https://doi.org/10.2307/j.ctt2250v4k.

Tehranian, John. 2007. "Infringement Nation: Copyright Reform and the Law/Norm Gap." Utah Law Review 3: 537-50. 